\title{
Ponhamos a casa abaixo - o Surrealismo português e sua proposta de renovação da arte e da vida
}

Luana Flavia Cota Drumond Universidade Federal de Minas Gerais

\begin{abstract}
"uma viagem que só terminará quando ardeu por completo não apenas o carvão que movia a locomotiva, mas a locomotiva, a estação de chegada, os rails e os passageiros."
\end{abstract}

M. Cesariny

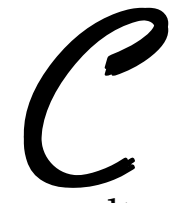

erca de 20 anos antes de o Surrealismo acontecer em Portugal, o movimento já tinha sido, por toda a Europa, especialmente na França, a expressão de uma revolta artística que pretendia transformar, além da arte e dos conceitos sociais, o modo de vida do sujeito burguês. Apesar do atraso - cujas razões serão discutidas neste artigo - em relação ao Surrealismo francês, a ação surrealista em Portugal foi forte e bastante representativa, travando embates políticos e sociais que até hoje repercutem na poesia lusitana.

A história do Surrealismo, entretanto, não começa na França, em 1924, ano em que André Breton publica o primeiro manifesto do movimento; desde Rimbaud, no século XIX, que a poesia reconhecia a insuficiência do real e se tentava descolar de sua representação, tentando expandir a realidade até que ela perdesse seus contornos nítidos e transcendesse a si mesma, 
indo em direção a uma irrealidade. ${ }^{1}$ O poeta simbolista, tempos antes de os surrealistas gritarem seus propósitos, já tentava promover, pela criação de imagens insólitas e metáforas improváveis e pelo uso de associações livres em sua poesia, por exemplo, a destruição do conhecido.

Esses elementos da obra rimbaudiana, depois explorados, desenvolvidos, levados ao limite pelo Surrealismo, são a expressão poética da recusa do escritor em participar do mundo como ele era: Rimbaud fez de sua rejeição do real partilhado algo fundamentalmente literário e transformou, assim, o processo criativo, trazendo para a poesia, tão, até lá, afeita à representação da realidade, a dimensão do desconhecido.

Após os anos simbolistas, o tempo do spleen, o século XX chegou apinhado de vanguardas artísticas, que enxergavam o homem como transformador da realidade e que, por isso, se propunham a renovar a arte, o comportamento e a sociedade, rompendo com o pensamento do século anterior. ${ }^{2}$ As revoluções europeias da segunda metade do século XIX haviam evidenciado as contradições sociais e desfeito a base da cultura, e a arte foi, assim, em meio ao decadentismo e à desilusão, afastando-se da realidade - destruída e privada de encantos.

As vanguardas europeias surgem com aspirações ao moderno, e o Futurismo, essencialmente italiano, buscou reproduzir em obras de arte as inúmeras ideias novas que circulavam pela nação, anunciando a ruptura com o passado e consagrando a técnica, a velocidade e a máquina. O estilo artístico agora deveria "ser rápido, ágil e revoloteante como la vida moderna en su incesante explosión y pulsación". ${ }^{3}$

${ }^{1}$ FRIEDRICH, 1978.

${ }^{2}$ MICHELI, 1981.

${ }^{3}$ MICHELI, 1981, p. 244. 
Ainda nos primeiros 15 anos do século XX apareceram o Cubismo e o Expressionismo, ambos ancorados em uma ideia de arte que superasse o real visível e "imediato", captado pela mera impressão de um olhar. Para os cubistas, que se queriam opor à arte impressionista do episódico, a essência das coisas era o que de fato se devia destacar, e isso não estava aparente. Era preciso, então, que o artista se permitisse criar um mundo próprio, abstrato, que alcançasse a forma interna das coisas, a sua estrutura, para, enfim, permitir uma compreensão mais profunda da realidade.

O Cubismo quis, numa época de propagação das teorias empíricas e fenomenológicas, fundadas, respectivamente, na observação experimental do mundo e na afirmação de que o mundo é o que nossa consciência capta, reafirmar a força do pensamento e da razão, fulcrais para o verdadeiro entendimento da vida.

Embora tenha se mostrado mais forte na pintura, em 1913, por um texto de Apollinaire, Les Peintres Cubistes, o Cubismo chegou às letras, e, então, passou a mostrar-se não só nas cores e formas criadas pelos artistas plásticos, mas também na quebra da sintaxe, na disposição aleatória de palavras numa folha, no desprezo pela pontuação, nas colagens incorporadas aos poemas, nos pensamentos expressos, situados entre o consciente e o inconsciente.

Para os expressionistas, a maior parte deles alemães, o mundo estava em desespero e o artista precisava fazer o retrato dessa realidade miserável a partir de si, com um olhar subjetivo. Mais uma vez, refutava-se a arte impressionista, dita "do golpe de vista", em favor de um olhar demorado e perspicaz sobre as coisas.

O Expressionismo, por suas inúmeras correntes, ganhou proporções tão dilatadas, que o movimento tornou-se difícil de definir. Houve vertentes que tomaram por princípios artísticos 
elementos diversos e, até, contrários aos de outras. É preciso ressaltar, contudo, como elas, embora guardassem entre si diferenças na forma, assemelhavam-se na revolta e no cantar de um mundo em desordem, e possuíam todas um agudo sentimento de crise.

Foi após a Primeira Guerra Mundial, com o Nazismo em crescimento, que o Expressionismo se viu encantonado. Como aquela noção de crise que os artistas possuíam não se podia, de modo algum, difundir, o governo nazista perseguiu e dispersou os expressionistas, tirou dos museus suas obras e as destruiu, porque a forma como eles demonstravam o fracasso da ordem fazia deles inimigos, ${ }^{4}$ e havia que se reduzir a nada aquele movimento.

Anos antes de o Expressionismo ser desfeito, o Dadaísmo aconteceu, começando na Suíça, em 1916. Dada não significava nada e justamente por isso, por não ter nenhum sentido no mundo, é que o termo foi escolhido para dar nome ao movimento cujo principal objetivo era rechaçar todas as noções existentes:

REPUGNÂNCIA DADAÍSTA

Todo e qualquer produto da repugnância susceptível de se tornar negação da família é dada; protesto de punhos cerrados de todo o ser em acção destrutiva: DADA; conhecimento de todo os meios até hoje rejeitados pelo sexo púdico do compromisso cômodo e da delicadeza: DADA; abolição da lógica, a dança dos impotentes da criação: $D A D A$; de todas as hierarquias e equações sociais instaladas pelos nossos lacaios com vista aos valores: DADA; cada objecto, todos os objectos, os sentimentos e as obscuridades, as aparições e o choque rigoroso das linhas paralelas constituem meios para o combate: DADA; abolição da memória DADA; abolição da arqueologia:

${ }^{4}$ MICHELI, 1981. 
$D A D A$; abolição dos profetas: $D A D A$; abolição do futuro: DADA; (...) Liberdade: DADA DADA DADA, rugido das dores crispadas, abraço dos contrários e de todas as contradições, dos grotescos, das inconsequências: A VIDA. ${ }^{5}$

A guerra fez crescer entre os intelectuais uma descrença no homem, um desgosto com a sociedade moderna - a mesma que os futuristas haviam cantado com orgulho, e eles passaram a negá-la, a negar seus princípios, sua razão e tudo o mais que com ela se relacionasse. Por causa disso, muitos consideram o Dadaísmo o movimento mais radical que jamais se viu, porque, em sua negação absoluta de tudo, conseguiu negar até mesmo a arte, enquanto fruto da civilização e dos valores humanos: "Así pues, Dada es antiartistico, antiliterario y antipoetico". 6

Em 1919, Marcel Duchamp, nas artes plásticas, chocou ao fazer sua própria Gioconda. Com bigodes. Era a tentativa dadaísta de dessacralizar a arte, de tirá-la de um lugar impassível, imutável e intocável em que, colocada pelos homens, ela permaneceu por tanto tempo. Para os artistas desse movimento, quase todos contrários ao envolvimento de seus países na Primeira Guerra Mundial, a arte como era então entendida não fazia mais sentido, deveria ser renovada em seus valores e no próprio conceito, porque não tinha sido capaz, assim como a ciência, de evitar a destruição da Europa.

Primordialmente, essa nova arte não deveria prescrever quaisquer normas. As vanguardas anteriores ditavam regras diferentes e, até, inovadoras, mas ditavam, e isso já era apresar o espírito. No Dadaísmo não haveria de existir ordem nem

5 TZARA, 1963, p. 19.

${ }^{6}$ MICHELI, 1981, p. 155. 
perfeição, o sujeito artístico precisava ser livre e espontâneo, porque nisso residia o espetáculo. Mas não só na arte, com toda essa ausência de normas, ou com o grotesco e o absurdo que então se apresentavam nas obras, a reforma era promovida, mas também no viver: $o$ artista que se quisesse parte do movimento precisava ter uma atitude dadaísta, uma postura que incorporasse a arte à vida e, misturando essas duas instâncias, fosse capaz de promover uma revolução no mundo. O escândalo seria sempre parte dessa ação.

Por fim, o Dadaísmo matou-se. Como movimento emergencial, que clamava pela descomposição da sociedade, ele não poderia durar muito, a ponto de adquirir uma identidade legitimada. Em Berlim, o término das ações dadaístas foi em 1920; entre os franceses sucessores de Rimbaud, em 1923.

Em 1919, mesmo ano da Gioconda de Duchamp, umas primeiras provas de escrita automática - método surrealista de fazer literatura - apareceram dentro do Dadaísmo, pelas mãos de Breton e Soupault, escritor e político francês, em Les Champs Magnétiques. Não demorou muito até que uma cisão se desse no movimento dadaísta e, então, o Surrealismo se desenhasse sob os auspícios do Primeiro Manifesto e atingisse patamares importantes nas artes europeias modernas.

O Manifesto Surrealista veio a público em 1924, declarando os princípios que regeriam o movimento e tencionando trazer para a arte dimensões desconhecidas do ser: as emoções, os impulsos, a imaginação - o inconsciente. Para o autor e os signatários, a atitude realista era medíocre e insuficiente diante da vida, e, no campo artístico, não poderia produzir mais do que obras horrendas; contido em excesso, o homem se estaria lançando em um destino negro. ${ }^{7}$

${ }^{7}$ BRETON apud VASCONCELOS, 1977. 
A influência da psicanálise na produção artística do Surrealismo é inegável, pelo que já se podia ver no Primeiro Manifesto, e também a das teorias marxistas. A revolução seria o único meio possível de a humanidade chegar à liberdade social, e o conhecimento psicológico a única forma de o homem libertar a si, por isso era preciso revolver a arte e a vida - a atitude surrealista de, indo além dos protestos e das críticas, tomar uma posição explícita e efetiva de transformação do mundo.

Fraturas entre sonho e realidade e a que se dava entre vida e arte já haviam sido percebidas pelo Dadaísmo e pelo Expressionismo, mas apenas o Surrealismo se propôs efetivamente a procurar soluções para isso, a pôr em contato os mundos exterior e interior, e por isso foi tão significativo no mundo artístico. Além disso, na busca por saídas para os problemas das artes, os surrealistas tentaram encontrar escapes também para a crise e a angústia européias, ${ }^{8}$ pregando a revolução geral e o desmanche das convenções, na união de real e fantasia.

Dos dadás, embora se quisessem rompidos com eles, os surrealistas adotaram o automatismo, a quebra da lógica, a aproximação aleatória, elementos estéticos como esses, que queriam trazer o absurdo e a incoerência para a superfície da expressão artística. De Rimbaud, a luta contra a arte que se transforma em objeto de consumo. Do Futurismo, a ideia de que a obra, se vai para museus, morre. Foi a proposta surrealista de uma nova sociedade, firmada sobre outras bases, que levou o movimento além das escolas e dos artistas anteriores.

Nesses anos de 1920, tempo em que na França apareciam os manifestos bretonianos e o Surrealismo se organizava com

${ }^{8}$ MICHELI, 1981. 
a força da revolução que pretendia ser, em Portugal a época ainda era a da Presença, o segundo Modernismo, que, embora conhecesse o que se passava na literatura francesa e até incorporasse alguns elementos da estética propagada por Breton, não se constituiu em vanguarda e não se afastou dos movimentos artísticos precedentes. Foi apenas na segunda metade dos anos 40, após o presencismo e a fase neo-realista da literatura portuguesa, que o arroubo surrealista, deslocado temporalmente e em suas características, chegou à Lusitânia.

Além de o Surrealismo em Portugal acontecer quando a voz do movimento já perdia o caráter político e as forças no resto da Europa - até na vizinha Espanha, sua história pouco tem que ver com a história da raiz francesa, porque tudo, inclusive os motivos para questionar o real, era diferente ali: os portugueses viviam a ditadura salazarista e acabavam de ver terminar o segundo embate mundial; as maneiras de pensar de então já não podiam entender o que se passava, era preciso uma linguagem que fizesse aflorar as questões portuguesas, que, compreendendo o problema, questionasse a ordem e sugerisse uma revolta artística.

OSurrealismo queria o rompimento com tudo, a destruição de todas as maneiras de pensar, e houve razões sociais para a sua demora em ancorar em Portugal, a começar pelo regime ditatorial do país, que limitava a criação, censurava as publicações e perseguia os autores ditos subversivos, especialmente os que propusessem tantas inovações ao povo. Era difícil, nessa circunstância, contou Cesariny, ${ }^{9}$ fazer um movimento, porque isso poderia significar ser preso, talvez morto. Quando, enfim, aportou em terras lusitanas, o Surrealismo insurgiu-se contra o discurso salazarista e a imagem de nação una e sólida que ele

${ }^{9}$ VASCONCELOS apud MARINHO, 1987. 
difundia, propondo à sociedade portuguesa um momento para repensar a si e o que era feito do país.

O momento neo-realista ainda não tinha passado quando, em 1942, no Café Herminius, o Surrealismo português começou a se formar. Poetas que um dia se declarariam surrealistas, tomaram, em fase primeira, parte no Neo-realismo, e, segundo Mário Cesariny (1997), foi porque consideravam esse movimento próximo demais de um "naturalismo ruim", abdicante da vanguarda estética e preocupado apenas com o conteúdo, que ele e companheiros como Pedro Oom o abandonaram para seguir com a revolução.

Em 1944, Jorge de Sena traduziu do francês para o português textos da fase mais surrealista, no que tange à estética, de vários autores do Surrealismo. Até então, o que se publicava em Portugal sobre o movimento francês, além de ser pouco, era a sua vertente mais engajada política e socialmente, porque, no momento de ditadura, isso era o que mais interessava aos portugueses. ${ }^{10}$ Sena, escolhendo e traduzindo textos que carregavam a inovação estética, abriu caminho-embora Cesariny o marginalizee não reconheça essa sua atitude surrealizante - para o Surrealismo começar a existir de fato em Portugal.

Três anos mais tarde, em 1947, regressando de Paris, onde travara contato com Breton e suas ideias, Mário Cesariny fundou o Grupo Surrealista de Lisboa, ao qual Alexandre O'Neill, António Domingues e João Moniz também juntaramse, todos declaradamente resolvidos a abalar as estruturas portuguesas. A reunião, entretanto, foi breve, porque em 1948, antes mesmo de qualquer atitude que afirmasse o grupo na sociedade literária, Cesariny separou-se dele, por discordar dos outros membros quanto à resubmissão de um artigo à censura do Estado. António Pedro, que continuava ligado ao

${ }^{10}$ MARINHO, 1987. 
GSL, recebeu do poeta uma carta que dizia de seus motivos: "Serve esta para dizer que me desligo inteiramente do chamado Grupo Surrealista de Lisboa, por não acreditar que seja Grupo e ainda menos que seja Surrealista". ${ }^{11}$

Então, Cesariny juntou-se a Pedro Oom, António Maria Lisboa e Henrique Risques Pereira no Grupo Surrealista Dissidente, cuja primeira comunicação foi feita em 1949, em uma sessão do J.U.B.A. - Jardim Universitário das Belas Artes, e chamou-se Afixação Proibida. Foi este o grupo que acabou por tornar-se mais forte na representação e na influência sobre os poetas que viriam; Mário Cesariny, seu artista mais emblemático.

No mesmo ano de 1949, os dois grupos montaram suas exposições: o GSL, em janeiro, na Travessa da Trindade, com um catálogo que, censurado pelo governo, trouxe apenas um $X$ vermelho alusivo na capa; o Dissidente, em junho, no Pathé Baby, com tão pouca repercussão quanto havia tido a anterior. Esta última ganhou o nome de I Exposição dos Surrealistas, numa mostra bem clara, por parte dos dissidentes, de que os membros do outro grupo não eram considerados legítimos surrealistas. Sobre a primeira, Mária de Fátima Marinho ${ }^{12}$ afirmou que ela marcou "o início oficial e o fim do Grupo Surrealista de Lisboa".

Polêmicas inúmeras acompanharam o Surrealismo português, marcado pelos constantes desentendimentos e expulsões dentro dos grupos, pelas querelas com artistas "de fora" do movimento, pela polarização entre o GSL e o Grupo Dissidente, cada qual reclamando a sua posição de mais autêntico surrealista. ${ }^{13}$ Essas polêmicas, somadas às publicações

${ }^{11}$ VASCONCELOS apud MARINHO, 1987, p. 45.

${ }^{12}$ MARINHO, 1987, p. 49.

${ }^{13}$ MARINHO, 1987. 
frustradas e às desavenças com Breton, que não reconhecia o Surrealismo Português, foram fulcrais para a desarticulação total dos grupos, e em 1952 já não havia um movimento organizado, mas indivíduos isolados a fazerem arte surrealista.

Para Adolfo Casais Monteiro (1965) - outro literato hostilizado por Mario Cesariny, apesar de ter sido um dos primeiros a teorizar sobre a escola surrealista em Portugal, o Surrealismo foi o único movimento da modernidade que entendeu as revoluções na vida e na arte como uma só e que as viveu indissociavelmente. Não era apenas a mudança estética na poesia e na pintura o que se evocava, mas uma atitude chocante e revolucionária, que transformasse, pelo escândalo, os conceitos da sociedade. Talvez essa tenha sido a mais marcante característica do Surrealismo português em si; os elementos técnicos, os jeitos de fazer a nova arte, isso os portugueses, na ausência de uma tradição local, absorveram dos franceses, ${ }^{14}$ mas a atitude que ofendia, que pretendia pôr a arder a cultura lusitana, embora também tenha sido aprendida do surrealismo bretoniano, foi tão forte e vividamente executada pelos artistas de Portugal, que marcou o movimento. Cesariny nos dá exemplos dos gestos escandalosos dos primeiros surrealistas portugueses:

afixação a cuspo, do que resulta o lento escorregar da matéria afixada, de imagens de generais e almirantes franceses. Saltos mortais para cima das mesas. Uivos graduados por José Leonel Martins Rodrigues. (...) Pedro Oom assoma velhas às esquinas. Uma cai. Grande corrida noturna atrás de Jorge Pelaio, afligido de espíritos, até os montes do Areeiro. Mário Cesariny traz para o café a máquina de escrever e um robe que pertenceu a Conchita Grandella. Os "ursinhos". Entrada de caçadores. Prisões de esperantistas. ${ }^{15}$

${ }^{14}$ MARINHO, 1987.

${ }^{15}$ VASCONCELOS apud WILLER, 2001. 
É relevante notar, embora haja importantes estudiosos que discordem, como o Surrealismo português montou um repertório próprio, não se limitando à aplicação dos preceitos franceses. Em Portugal, os elementos que haviam sido absorvidos da vertente francófona do movimento ganharam a luz do momento histórico vivido e da coragem dos artistas de tornarem públicos os seus projetos para a arte, batendo-se contra a ditadura, a sociedade, as tradições e o próprio Surrealismo.

Fora da França, o Surrealismo Português talvez tenha sido o que mais gerou efeitos na poesia e na mudança de postura do artista. Mário Cesariny, a grande figura do movimento, manteve-se radicalmente surrealista até o fim, aos mais de 80 anos de idade. "Exercício Espiritual", poema contido em Manual de Prestidigitação, ${ }^{16}$ exemplifica bem a proposta surrealista de implodir os costumes e as artes portuguesas e reconstruí-los diferentes, novos e inovadores:

É preciso dizer rosa em vez de dizer ideia

é preciso dizer azul em vez de dizer pantera é preciso dizer febre em vez de dizer inocência

é preciso dizer o mundo em vez de dizer um homem

É preciso dizer candelabro em vez de dizer arcano

é preciso dizer Para Sempre em vez de dizer Agora

é preciso dizer O Dia em vez de dizer Um Ano

é preciso dizer Maria em vez de dizer aurora

${ }^{16}$ VASCONCELOS, 2005, p. 128. 


\section{Referências}

AUTOGRAFIA: Um filme sobre Mário Cesariny. De Miguel Gonçalves Mendes. Lisboa: Clap, 2004. 1 disco.

CASAIS MONTEIRO, Adolfo. A palavra essencial: estudos sobre a poesia. São Paulo: Ed. da USP, 1965.

FRIEDRICH, Hugo. Estrutura da Lírica Moderna: da metade do século XIX a meados do século XX. São Paulo: Duas Cidades, 1978.

MARINHO, Maria de Fátima. O Surrealismo em Portugal. Lisboa: Imprensa Nacional - Casa da Moeda, 1987.

MICHELI, Mario de. Las vanguardias artísticas del siglo XX. Madrid: Alianza Editorial, 1981.

TZARA, Tristan. Sete Manifestos Dada. Lisboa: Hiena Editora, 1963.

VASCONCELOS, Mário Cesariny de. A intervenção surrealista. Lisboa: Assírio e Alvim, 1997.

VASCONCELOS, Mário Cesariny de. As mãos na água a cabeça no ar. Lisboa: Assírio e Alvim, 1985.

VASCONCELOS, Mário Cesariny de. Manual de Prestidigitação. Lisboa: Assírio e Alvim, 2005, 2ª edição.

VASCONCELOS, Mário Cesariny de. Textos de afirmação e de combate do Movimento Surrealista Mundial. Lisboa: P\&R, 1977.

WILLER, Claudio. A permanência da anarquia: a propósito de uma antologia do Surrealismo português. Revista Agulha. São Paulo, Fortaleza, número 10, mar. 2001. Disponível em: <http:// www.revista.agulha.nom.br/ag10willer.htm $>$. Acesso em: out. 2012. 


\section{Resumo}

O tardio Surrealismo português - década de 1940 significou uma revolução na cultura lusitana e no próprio movimento, surgido na França dos anos 1920. Em Portugal, o momento histórico ajudou a moldar uma ação surrealista polêmica, escandalosa e com repertório próprio. Ler a poesia desse movimento é essencial para compreender o papel que teve a vanguarda na transformação da sociedade e da cultura portuguesas.

\section{Abstract}

Le tardif Surréalisme portugais - décennie 1940 - a signifié une révolution dans la culture portugaise et dans le propre mouvement surgit dans la France les années 1920. Au Portugal, le moment historique a aidé mouler une action surréaliste polémique, scandaleuse et avec un répertoire propre. Lire la poésie de cette mouvement est essentiel pour comprendre le rôle qui l'avant-garde avait dans la transformation de la société et de la culture portugaises. 